uncle, but not till after his classical "Rapport" (of 1867, not 1868, as on pp. 201, 234, $426)$; quite rightly, he is always referred to in the text by his paternal name, without the later addition, and should be so noted in the index. Under "Schiller" philosophy has been substituted for history. "AEnesidemus" is correctly printed under "Schulze, G. E.," incorrectly on p. $\mathrm{i}$ of the index. Under "Ueberweg," T. M. should be substituted for J. M. Lindsay; and "Taylor" should read Tayler. The caption "Cause and effect defined" should be thoroughly revised and extended. There are several references in the text of far greater importance than the single one recorded in the index.

\section{ANN ARBor}

\section{R. M. WENLEY}

\section{Electrical Machine Design. By Alexander} Gray. McGraw Hill Book Company.

"Electrical Machine Design," by Alexander Gray, discusses the theory of operation and design of direct current generators and motors of both interpole and non-interpole type, alternating current generators, induction motors and transformers. Five hundred and seven pages are not enough to cover such a range of subjects satisfactorily, and when the analysis of theory is carried to the extent attempted by Mr. Gray the result can not be a success. Considered as a text-book, it would be unsuited to the average fourth-year student, not because the analyses are too involved for such, but because their introductions are too brief. The calculation of temperature gradient may be taken as an example. If a few paragraphs had been inserted discussing the laws governing flow of heat, and containing perhaps a simple application, the subsequent treatment would have been much more easily understood. The same criticism is applicable to the chapter on armature reactions in alternators.

Considered as a book for reference purposes, this work contains much matter of value, both to the student and to the designer. Discussions of such questions as noise of induction motors, comparative value of shell and core type transformers, short pitch windings in direct current machines, are really valuable and are not to be found readily elsewhere. The subjects of commutation and insulation are very well developed.

The arrangement of subject matter is usually excellent. The treatment of the induction motor had better have followed that of the transformer instead of preceding it. Such an arrangement would have made possible the consideration of the induction motor as a transformer, a most practical and effective method. The theory of operation and construction of each type of apparatus is first developed. This is followed by the procedure in design, the discussion of special types of machines, and a chapter on specifications. Examples accompany the text and should aid the student materially in his comprehension of the subject.

The book compares favorably with the other books on design in our language, but when it is contrasted with the simple and extremely logical treatments to be found in the works of Arnold, its own shortcomings are most apparent.

C. W. Green

\section{METEOROLOGICAL OBSERVATIONS AT THE UNIVERSITY OF CALIFORNIA}

IT is probably due to the fact that the public interest in meteorology is centered around weather forecasts that the science has received so little attention from the universities of the United States. The University of California is one of the relatively small number which has maintained a regular series of observations for a considerable period.

Until July 1, 1912, when the routine meteorological work at Berkeley was transferred to the department of geography under which the courses in meteorology and climatology are listed, the astronomy departments, the Lick Observatory at Mount Hamilton and the Students' Observatory at Berkeley, carried on the principal meteorological observations of the university. Meteorological observations have always been a part of the regular work of the Lick Observatory and, when the Students' Observatory was established at Berkeley, its ac- 